\section{EFFECTIVENESS OF INTERVENTIONS TO PREVENT MOTORCYCLE INJURIES: SYSTEMATIC REVIEW OF THE LITERATURE}

${ }^{1}$ Miguel Araujo, ${ }^{2}$ Eduardo Illanes, ${ }^{3}$ Eugênia Maria Silveira Rodrigues, ${ }^{3}$ Evelina Chapman. ${ }^{1}$ Clínica Indisa (Santiago, Chile); Medwave Estudios Ltda (Santiago, Chile); ${ }^{2}$ Medical School Faculty, Universidad Mayor; Barros Luco Hospital Complex (Santiago, Chile); ${ }^{3}$ Pan American Health Organisation/World Health Organisation (Washington,DC -USA)

\subsection{6/injuryprev-2016-042156.894}

Background In the Region of the Americas, the proportion of motorcycle deaths rose from $15 \%$ to $20 \%$ of the total road traffic deaths between 2010 and 2013.

Methods Studies included had to evaluate the effectiveness of preventive interventions aimed at motorcycle crashes or traffic crashes in general that provided objective measurements on the frequency of crashes or their effects in terms of mortality, injuries or sequelae. Systematic reviews were selected that included a description of the bibliographic search methods and the criteria for eligibility of the studies.The review was complemented with primary studies that have been published since 2000 .

Results The measures were analysed as follows: Effective measures: Compulsory training before obtaining a license; Non-compulsory training that, once approved, makes it possible to obtain a license; Use of helmets; Protective clothes; Anti-lock brakes. Potentially effective measures: Low-speed zones in urban areas; Blood alcohol concentration of $0.08 \mathrm{~g} / \mathrm{dL}$; Administrative revocation of license (e.g., for refusing to take a blood alcohol test); Greater penalties for alcohol; Greater penalties for speeding; Skill test requirement to obtain a license; More restrictions on obtaining a license. Ineffective measures: Zero tolerance alcohol laws $(0.00 \mathrm{~g} / \mathrm{dL}$ for $<21$ years); Allowing driver sobriety checkpoints ; Use of lights during day driving; Traffic calming interventions to the urban road network; Non-compulsory training. Measures not well evaluated: Graduated licensing; Restriction on engine power on motorcycles used by young rivers; Protective devices for the legs; Reflecting clothes; Measures for fatigue.

Conclusions This report has presented an up-to-date summary of the evidence on the effectiveness of various measures to prevent motorcycle crashes and their consequences that can be used as a reference by road traffic experts and decision-makers.

\section{ACCEPTABILITY OF AN M-HEALTH INTERVENTION TO IMPROVE CHILD-PASSENGER SAFETY IN IBADAN, NIGERIA}

Adesola Olumide, Emmanuel Adebayo, Eniola Cadmus, Yetunde Folajimi, Olukemi Amodu, Folusho Balogun. University of Ibadan

\subsection{6/injuryprev-2016-042156.895}

Background Child car-passenger safety practices remain low in Nigeria. We present findings from the formative phase of a project to deliver an m-health intervention on child-passenger safety to mothers/caregivers attending selected child-immunisation clinics in Ibadan. The aims were to describe: current legal provisions and awareness of child-passenger safety measures, acceptability of a mobile-phone intervention to improve child-passenger safety and availability and costs of standard age-appropriate child seats. Methods Twenty-three key-informant interviews [with enforcement officers (4), doctors (3), teachers (3) and mothers of infants and school-age children (11)] and a market survey were conducted. Data were analysed with ATLAS.ti.
Results Current laws do not directly address child safety although the Highway Code stipulates that child-passengers should be restrained in age-appropriate seats and those $\leq 12$ years should sit at the back. Most interviewees were aware of the need to use infant seats but not of the need for child-and booster seats. Some barriers to the use of child carseats were lack of knowledge of its importance and cost. Interviewees felt enactment and enforcement of laws and enlightenment were necessary for compliance. Acceptance of a mobile-phone intervention, (although not necessarily a mobile application), was very high. Participants stated that it was cost-effective and convenient. Interviewees suggested the use of calls, bulk SMS, twitter ${ }^{\circledR}$ and facebook ${ }^{\circledR}$. Twelve retail stores selling items for children were visited. Most stores had about two to three seats each because of low demand. Barelyused and brand new age-appropriate seats were available although infant seats were mostly seen. Most seats had appropriate standard labels. One barely-used booster seat (cost:\$30) was seen. Costs of infant seats ranged from $\$ 25-\$ 180$ and toddler seats, $\$ 30-\$ 405$.

Conclusions Findings indicate that an $\mathrm{m}$-health intervention is acceptable and would be timely in improving car-passenger safety practices among the study participants.

\section{CAUSES AND EFFECTS OF ROAD TRAFFIC ACCIDENTS IN POLAND}

${ }^{1,2}$ Krzysztof Goniewicz, ${ }^{3}$ Mariusz Goniewicz. ${ }^{1}$ Polish Air Force Academy, Poland; ${ }^{2}$ Medical University of Warsaw, Poland; ${ }^{3}$ Medical University of Lublin, Poland

\subsection{6/injuryprev-2016-042156.896}

Background Every year, several thousand people are killed on Polish roads and tens of thousands get injured. In Poland, road accidents are the first cause of death in case of men up to 44 years of age. The most common, permanently occurring causes of road accidents include failure to comply with the rules of the road traffic, low driving skills combined with a poor assessment of the situation on the road, lack of adequate road infrastructure as well as poor technical conditions of vehicles. The article presents the epidemiology of road accidents in Poland in the years 2004-2014 focusing on the main problems of road safety.

Methods The analysis was based on the reports of Prevention and Analysis Office of Road Traffic Headquarters of Police from the years 2004 to 2014 as well as the information included in National Road Safety Programme- GAMBIT 2005, National Road Safety Programme 2013 to 2020 and Strategy for Efficient State in 2020.

Results The analysis enumerates as the main cause for the higher rate of severe accidents in Poland: inappropriately adjusted speed by a driver to traffic conditions, careless pedestrian entrance on the road in front of a moving vehicle, the state of intoxication in case of both drivers and pedestrians, poor technical state of vehicles prevailing on Polish roads, bad roads and the lack of modern infrastructure relevant to the current consumer needs, large collisions in traffic resulting from the improper design of roads, often careless organisation, and the lack of traffic segregation, lack of the knowledge of first aid among road users, ineffective emergency rescue systems on roads.

Conclusions Despite various measures that are being taken to improve safety on Polish roads, the number of the dead and wounded as a result of road accidents is still very high and the losses incurred by the society are high as well. It is necessary to continue multidirectional actions to improve safety on the roads 